\title{
Mucosal Protection by Phosphatidylcholine
}

\author{
Wolfgang Stremmel Robert Ehehalt Sabine Staffer Sabine Stoffels \\ Andrea Mohr Max Karner Annika Braun \\ Department of Gastroenterology, University Hospital Heidelberg, Heidelberg, Germany
}

\section{Key Words}

Mucus $\cdot$ Phosphatidylcholine $\cdot$ Ulcerative colitis

\begin{abstract}
The colonic mucus serves a first barrier towards invasion of commensal bacteria in stools to prevent inflammation. One essential component of intestinal mucus is phosphatidylcholine (PC) which represents more than $90 \%$ of the phospholipids in mucus indicative for a selective transport of PC into this compartment. It is arranged in lamellar structures as surfactant-like particles which provide a hydrophobic surface on top of the hydrated mucus gel to prevent the invasion of bacteria from intestinal lumen. In ulcerative colitis (UC), the mucus PC content is reduced by $70 \%$, irrespective of the state of inflammation. Thus, it could represent an intrinsic primary pathogenetic condition predisposing to bacterial invasion and the precipitation of inflammation. Since PC was shown to be mainly secreted by the ileal mucosa from where it is assumed to move distally to the colon, the PC content along the colonic wall towards the rectum gradually thins, with the least PC content in the rectum. This explains the start of the clinical manifestation of UC in the rectum and the expansion from there to the upper parts of the colon. In three clinical trials, when missing mucus PC in UC was supplemented by an oral, delayed release PC prepara-
\end{abstract}

tion, the inflammation improved and even resolved after a 3-month treatment course. The data indicate the essential role of the mucus PC content for protection against inflammation in colon.

Copyright $\odot 2012$ S. Karger AG, Basel

\section{State of the Art}

Ulcerative colitis (UC) is a common chronic inflammatory disease in adults and children. It is defined as a diffuse inflammatory condition of the colonic mucosa that starts in the rectum and might extend to the cecum, causing erosion, ulceration and fibrotic repair. Manifestations are pancolitis (approx. 20\%), right-sided colitis (approx. 5\%), left-sided colitis (approx. 30\%), proctosigmoiditis (approx. 20\%) and proctitis (approx. 25\%). The most typical symptoms are bloody diarrhea and pain during bowel movements.

The etiology of UC is unknown. Based on epidemiological examinations, it is surmised that along with a genetic disposition environmental factors trigger the disease. A disturbed mucosal barrier is thought to be an initiating factor of the disease and subsequent attacks from the colonic commensal bacterial flora result in inflammation of the mucosa [1-3].

\section{KARGER}

Fax +4161306 1234

E-Mail karger@karger.ch

www.karger.com
(C) 2012 S. Karger AG, Basel

0257-2753/12/0309-0085\$38.00/0

Accessible online at:

www.karger.com/ddi
Prof. Dr. Wolfgang Stremmel

Abteilung Innere Medizin IV (Gastroenterologie, Infektionskrankheiten, Vergiftungen) Universitätsklinikum Heidelberg, Medizinische Universitätsklinik Heidelberg Im Neuenheimer Feld 410, DE-69120 Heidelberg (Germany)

E-Mail wolfgang_stremmel@med.uni-heidelberg.de 


\section{The Mucosal Barrier}

The major physiological functions of the colon are the absorption of water and minerals, and the formation and discharge of feces containing mainly bacteria and nonabsorbable fibers. Concentrations of up to one trillion microbes per gram of stool are present in the colon and the distribution among the different bacterial species remains astonishingly constant in each individual over long periods of time [4]. Despite this enormous concentration of commensal microbes, the mucosa remains intact, and inflammation, erosions or ulcerations are not observed under physiological conditions. This is due to the nature of the mucosal barrier. Defensive mechanisms prohibit the invasion of bacteria and the mucosa-associated immune system remains quiescent. When bacteria invade the mucosa, the immune system is rapidly activated to prevent (as a last bid) systemic translocation and sepsis. This activation is associated with an inflammatory response and apoptotic reactions (collateral damage) to defend against further invasion of bacteria. The mucosal barrier consists of the densely packed mucosal cell layer connected by tight junctions. The most important component of the barrier, however, is the mucus layer as the first line of defense. Within this compartment, a high concentration of defensins is present; these are actively secreted into the mucus [5]. They are small proteins which are highly conserved within the phylogenetic tree, and are responsible for eliminating invading bacteria by punching holes in the bacterial membranes in order to destroy them [6].

The structural constitution of the mucus is essential for the barrier function. It is organized as a hydrated polymeric gel with a thickness of up to $830 \mu \mathrm{m}$ in the colon [7]. It is maintained by a network composed of the glycoprotein family of mucins (e.g. MUC 2) which are strongly negatively charged $[8,9]$. Although only little is known about the regulation and spacial distribution of the mucus scaffold components, it is evident that there are two layers with different properties and functions [10]. The lower layer $(50 \mu \mathrm{m})$ is densely packed, devoid of bacteria and firmly attached to the epithelium. The upper layer is easily removable and contains mucins, cell debris and bacteria and may represent a turnover 'garbage' compartment for the lower, highly organized layer before it is lost to the lumen [11].

Most internal surfaces of the organism consist of mucosal membranes which produce mucus with high concentrations of phosphatidylcholine (PC) [12-14]. These phospholipids are arranged in lamellar structures associ- ated with specific proteins. In the lung, these lamellar bodies constitute the 'surfactant' and it has long been ignored that such 'surfactant-like particles' are also present in the intestinal mucus [15]. While the surfactant of the lung is known to play a role in gas exchange, surfactantlike particles in the colon could - in addition to a possible role in substrate absorption - be useful, particularly to protect against the invasion of bacteria $[14,15]$. PC has amphiphilic characteristics with a positively charged polar headgroup (phosphorylcholine) and a nonpolar hydrocarbon (fatty acid) tail. As the mucin network is strongly negatively charged, the PC head-group is believed to be electrostatically bound to the mucin network forming a monolayer with the fatty acid chains extending luminally [16]. This establishes a hydrophobic surface on top of a hydrated gel which prevents the adherence and penetration of bacteria, i.e. it repels luminal content by acting like a closing seal $[17,18]$.

\section{Evidence for Impaired Mucus Phosphatidylcholine Secretion in Ulcerative Colitis}

The fact that within the fraction of phospholipids in mucus $>90 \%$ represent PC or lysophosphatidylcholine indicates that there is a selective transport process for PC into this compartment. When radiolabeled PC was injected into the tail veins of rats, it was detected in the bile (as expected) and to a similar extent in the small intestine and to a (significantly) lesser degree in the colon [19] (fig. 1).

The question remains whether a low PC abundance in the colon represents the reduced PC secretion capacity of the colonic mucosa itself or is just a consequence of the minor mucosal surface area compared to the ileum. The mechanism involved in the luminal PC secretion across the intestinal wall is still unclear. First, it has to be determined whether PC is synthesized by the mucosal cells or whether it is recruited from blood, for instance, from lipoproteins. The next question is whether PC is secreted by mucosal cells or traverses the mucosal barrier by passing through the tight junctions, as suggested by Alpers et al. [20, 21].

The above-mentioned intestinal PC recovery studies (injection of radiolabeled PC into the tail veins of rats) indicate that it may be the intact PC which is translocated into the mucus [19]. It was noted that the PC translocation was stimulated by the presence of taurocholate in the perfusion medium. This suggests that the detergent-like properties of bile acids stimulate the vectorial 
Fig. 1. Respective $\left[{ }^{3} \mathrm{H}\right]-\mathrm{PC}$ secretion rates in the jejunum, ileum, colon $\left(\mathrm{fmol} \times \mathrm{h}^{-1}\right.$ $\times \mathrm{cm}$ intestine $\mathrm{e}^{-1}$ ) and liver $\left(\mathrm{fmol} \times \mathrm{h}^{-1} \times\right.$ $\mathrm{g} \mathrm{liver}^{-1}$ ) of male rats in the presence of $2 \mathrm{~mm}$ TC. $\left[{ }^{3} \mathrm{H}\right]-\mathrm{PC}$ was injected intravenously at time point 0 . After $30 \mathrm{~min}$, the secretion rates of each of the intestinal segments reached equilibrium and were significantly different from one another.

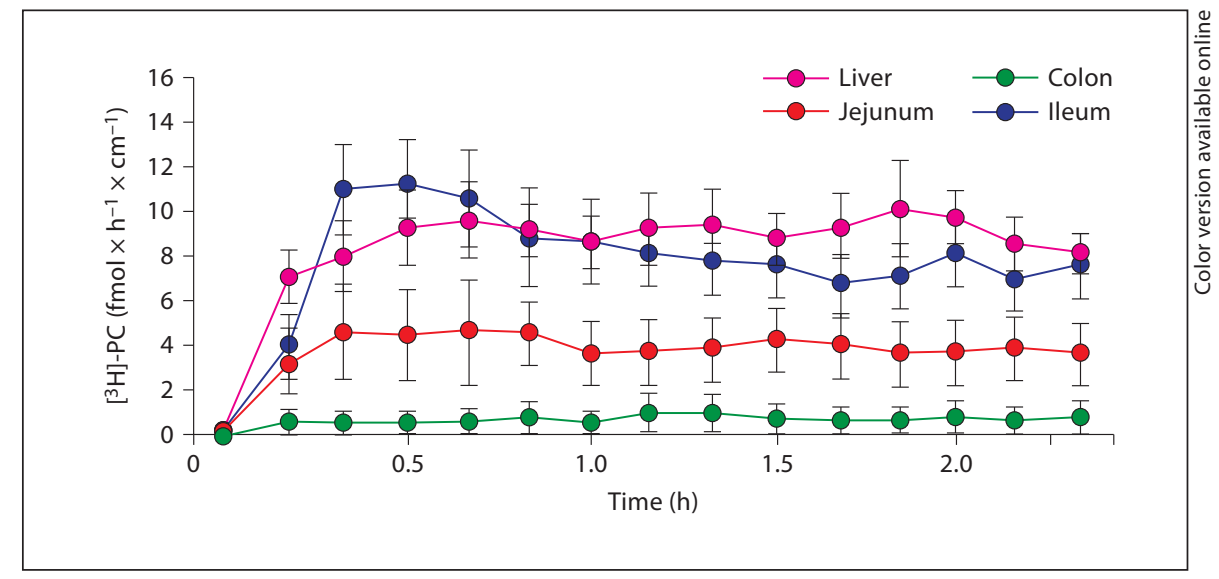

transport into the intestinal lumen. It may indicate a yet unknown functional role of bile acids in the distal small intestine where adsorption of fatty acids is already completed and before bile acids are reabsorbed in the terminal ileum.

\section{Low Phosphatidylcholine in Colonic Mucus as a Key Pathogenetic Factor in Ulcerative Colitis}

The finding is intriguing that $\mathrm{PC}$ is reduced by about $70 \%$ in the mucus of the rectal mucosa of patients with UC, independent of the state of inflammation [22] (fig. 2).

It has also been shown that in the terminal ileum and colon transversum, the mucus PC is markedly reduced compared to controls and patients with Crohn's disease (CD) [23] (table 1).

A lack of $\mathrm{PC}$ in the mucus has functional consequences. Below a certain threshold concentration of PC in mucus, the hydrophobic barrier is broken and commensal bacteria can attack. As a surrogate marker of this impairment, the surface tension of the mucus can be determined [15]. In fact, it was shown that the surface tension of the mucus is significantly reduced in UC compared to CD and controls [24] (fig. 3).

\section{Hypothesis for Impaired Mucus Phosphatidylcholine Secretion in Ulcerative Colitis}

The mechanisms involved in the reduced mucosal PC concentration have still to be elucidated. It may represent a multifactorial process, possibly involving the different steps of mucosal PC synthesis and/or intracellular traf-



Fig. 2. Concentration of representative PC and LPC species in rectal mucus obtained from controls and from CD and UC patients [22].

ficking, cellular excretion and translocation/incorporation into the mucus (e.g. binding to the mucin network).

Proper mucosal cell function requires attachment to the basal membrane as well as lateral adhesion via integrin activation. The significance of the tight junction proteins was recently highlighted by functional studies demonstrating the kindlin protein family as essential partners in the cell-basal membrane as well as cell-cell adhesion process [25]. Indeed, deletion of the kindlin-1 gene in mice resulted in a perinatally lethal UC phenotype [26]. It could indicate a loss of mucosal cell function due to the detachment of mucosal cells from the basal membrane or the loss of adherence to each other. The most obvious explanation is that the mucosal cell layer is 
Table 1. Total concentrations and molecular species composition of PC, LPC and sphingomyelin in colonic mucus from controls and from CD and UC patients

a Source of PC

\begin{tabular}{|c|c|c|c|c|c|c|c|c|c|}
\hline & $\begin{array}{l}\text { PC 32:0 } \\
(734 \mathrm{Da})\end{array}$ & $\begin{array}{l}\text { PC 34:2 } \\
(758 \mathrm{Da})\end{array}$ & $\begin{array}{l}\text { PC 34:1 } \\
(760 \mathrm{Da})\end{array}$ & $\begin{array}{l}\text { PC 36:4 } \\
(782 \mathrm{Da})\end{array}$ & $\begin{array}{l}\text { PC 36:3 } \\
(784 \mathrm{Da})\end{array}$ & $\begin{array}{l}\text { PC 36:2 } \\
(786 \mathrm{Da})\end{array}$ & $\begin{array}{l}\text { PC 36:1 } \\
(788 \mathrm{Da})\end{array}$ & $\begin{array}{l}\text { PC 38:4 } \\
(810 \mathrm{Da})\end{array}$ & $\begin{array}{l}\text { Total PC } \\
\text { pmol/100 } \\
\mu g \text { protein }\end{array}$ \\
\hline Con & $5.2 \pm 0.6$ & $18.5 \pm 0.9$ & $28.5 \pm 0.7$ & $7.9 \pm 0.7$ & $9.9 \pm 1.1$ & $15.4 \pm 0.6$ & $9.9 \pm 0.5$ & $4.7 \pm 0.3$ & $2,790 \pm 354$ \\
\hline $\mathrm{CD}$ & $5.5 \pm 1.1$ & $17.2 \pm 1.4$ & $30.7 \pm 1.3$ & $8.1 \pm 1.4$ & $9.5 \pm 0.7$ & $15.6 \pm 2.8$ & $9.4 \pm 0.5$ & $4.0 \pm 0.5$ & $2,450 \pm 431$ \\
\hline \multirow[t]{3}{*}{ UC } & $13.3 \pm 1.8$ & $13.1 \pm 1.0$ & $27.7 \pm 1.4$ & $6.4 \pm 1.0$ & $8.3 \pm 1.1$ & $12.9 \pm 1.1$ & $14.5 \pm 1.6$ & $3.8 \pm 0.8$ & $745 \pm 148$ \\
\hline & vs. $\operatorname{Con}^{* * *}$ & vs. $\operatorname{Con}^{* * *}$ & & vs. Con ${ }^{* *}$ & & vs. $\operatorname{Con}^{* *}$ & vs. $\operatorname{Con}^{* * *}$ & & vs. $\operatorname{Con}^{* * *}$ \\
\hline & vs. $\mathrm{CD}^{* * *}$ & vs. $\mathrm{CD}^{* * *}$ & & & & & vs. $\mathrm{CD}^{* * *}$ & & vs. $\mathrm{CD}^{* * *}$ \\
\hline
\end{tabular}

b Source of LPC or SM

\begin{tabular}{|c|c|c|c|c|c|c|c|c|c|}
\hline & $\begin{array}{l}\text { LPC 16:0 } \\
(496 \mathrm{Da})\end{array}$ & $\begin{array}{l}\text { LPC 18:1 } \\
(522 \mathrm{Da})\end{array}$ & $\begin{array}{l}\text { LPC 18:2 } \\
(524 \mathrm{Da})\end{array}$ & $\begin{array}{l}\text { Total LPC } \\
\text { pmol/100 } \mu \mathrm{g} \\
\text { protein }\end{array}$ & $\begin{array}{l}\text { SM 16:0 } \\
(703 \mathrm{Da})\end{array}$ & $\begin{array}{l}\text { SM 24:2 } \\
(811 \mathrm{Da})\end{array}$ & $\begin{array}{l}\text { SM 24:1 } \\
(813 \mathrm{Da})\end{array}$ & $\begin{array}{l}\text { SM 24:0 } \\
(815 \mathrm{Da})\end{array}$ & $\begin{array}{l}\text { Total SM } \\
\text { pmol/100 } \mu \mathrm{g} \\
\text { protein }\end{array}$ \\
\hline $\mathrm{CD}$ & $61.2 \pm 3.1$ & $16.6 \pm 2.8$ & $22.2 \pm 1.4$ & $2,675 \pm 346$ & $43.8 \pm 3.0$ & $16.9 \pm 1.5$ & $21.6 \pm 2.6$ & $17.7 \pm 1.6$ & $395 \pm 71$ \\
\hline UC & $60.5 \pm 3.0$ & $17.1 \pm 2.4$ & $22.4 \pm 1.9$ & $\begin{array}{l}1,572 \pm 333 \\
\text { vs. } \operatorname{Con}^{* * *} \\
\text { vs. } \mathrm{CD}^{* *}\end{array}$ & $52.3 \pm 3.8$ & $12.3 \pm 1.8$ & $19.8 \pm 1.9$ & $15.6 \pm 2.1$ & $411 \pm 63$ \\
\hline
\end{tabular}

Con = Controls; $\mathrm{SM}=$ sphingomyelin. ${ }^{* *} \mathrm{p}<0.01,{ }^{* *} \mathrm{p}<0.001$.

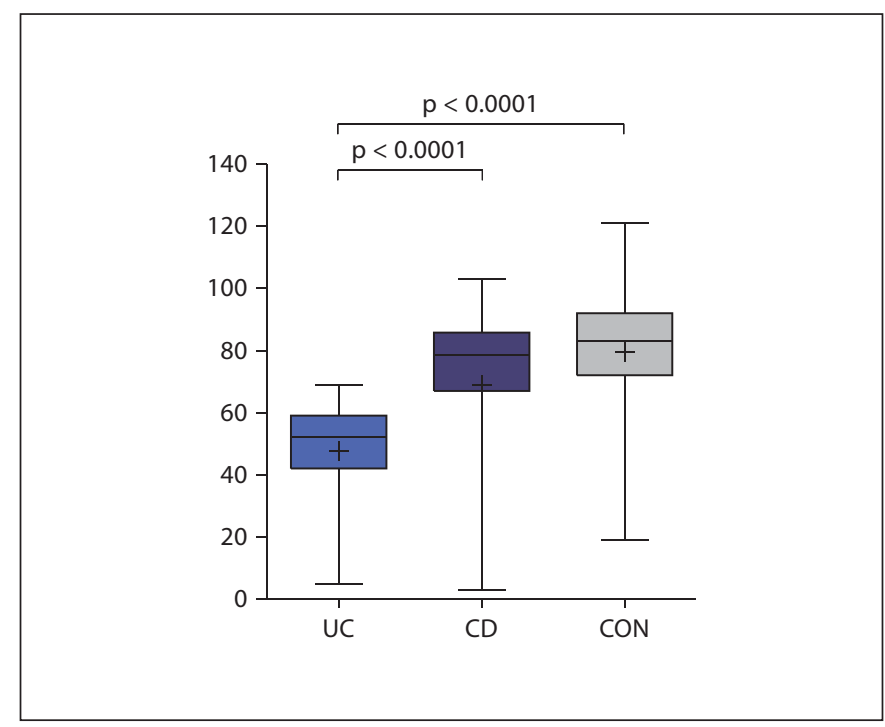

Fig. 3. Colonic luminal surface hydrophobicity of 19 patients with UC, 10 with CD and 20 control subjects (CON) was compared. Patients with UC had a significantly lower surface hydrophobicity (contact angle) than CD patients and controls, between whom no significant difference was detected. Overall: $p=0.0002$, UC vs. CD: $p<0.05$, UC vs. CON: $p<0.05$. Data are expressed as median and IQR [24]. disrupted and, thus, the commensal bacteria in stools can easily penetrate and induce inflammation. An alternative more speculative hypothesis is based on the suggestion of Alpers et al. [20] and Engle et al. [21], that PC could selectively traverse the tight junctional barrier for enrichment in the mucus layer. Thus, a disturbed tight junctional arrangement could impair mucosal PC permeability resulting in a low mucus PC content. Those processes are at present being evaluated in our laboratory.

\section{Low Mucus Phosphatidylcholine and the Clinical Manifestation of Ulcerative Colitis}

Irrespective of the underlying mechanism, it can be proposed that a lack of PC in mucus is a specific pathogenetic feature of UC [27-29]. It is the inherent low mucus PC content of as little as $30 \%$ compared to controls and patients with $\mathrm{CD}$ which impairs the mucosal barrier in UC. The finding that mucus PC is low irrespective of the inflammatory activity [22] indicates that it represents an intrinsic primary defect which precipitates inflammation under certain conditions. The low mucus PC content may 
be sufficient to maintain a labile intact barrier function in asymptomatic patients with UC. Yet unknown factors may further reduce the mucus PC concentration below a critical threshold where the mucosal barrier is broken, followed by precipitation of an inflammatory episode. Under discussion are the hormonal changes or additional environmental factors such as viral infections or, in particular, changes of the commensal flora towards strains with high phospholipase activities which further reduce the available protective $\mathrm{PC}$ within the mucus. On the other hand, colonization with low phospholipase active strains, e.g. Escherichia coli Nissle, may protect from the critical breakdown of the PC barrier.

As bile acids in the distal small intestine could promote the PC secretory activity, it is conceivable that a low bile acid concentration in cholestatic disorders, e.g. primary sclerosing cholangitis, impairs the PC secretion and contributes to the manifestation of UC.

The fact that PC secretion occurs mainly in the small intestine, particularly in the distal ileum and less in the colon [19], may predispose to the observed exclusive colonic manifestation of UC. Thus, we originally proposed that the PC layer thins towards the rectum. This could be explained by the hypothesis that the mucus moves from the ileum to the rectum and that by exposure to phospholipases of the commensal flora, the rectum represents the 'last lawn' of PC content in mucus. The movement of mucus concerns mainly the upper loosely attached layer. On the other hand, it would also be plausible that due to a higher concentration of bacteria in more consolidated stools and a longer time of exposure in the rectum, bacterial phospholipases exert more activity. This would explain the start of inflammation in the rectum and the expansion from there to upper parts of the colon. The theory of downward-moving mucus is in line with the hypothesis that the lower the PC content in the mucus, the greater the extent of the disease with the least PC content in pancolitis. A primary low $\mathrm{PC}$ secretion capacity in the small intestine as a key pathogenetic feature in UC could also explain the phenomenon of pouchitis in the ileoanal pouch after colectomy for UC. Indeed, pouchitis after colectomy for UC is observed in up to $70 \%$ of cases. However, in most instances, it is a mild to moderate inflammation and only in around $10 \%$ does severe pouchitis occur. In contrast, the ileoanal pouch after colectomy for familial adenomatous polyposis almost never leads to pouchitis. We propose that the PC secretory capacity is significantly reduced in UC pouch mucosa compared to in familial adenomatous polyposis. This fits with the notion that the PC mucus barrier is impaired and the com-

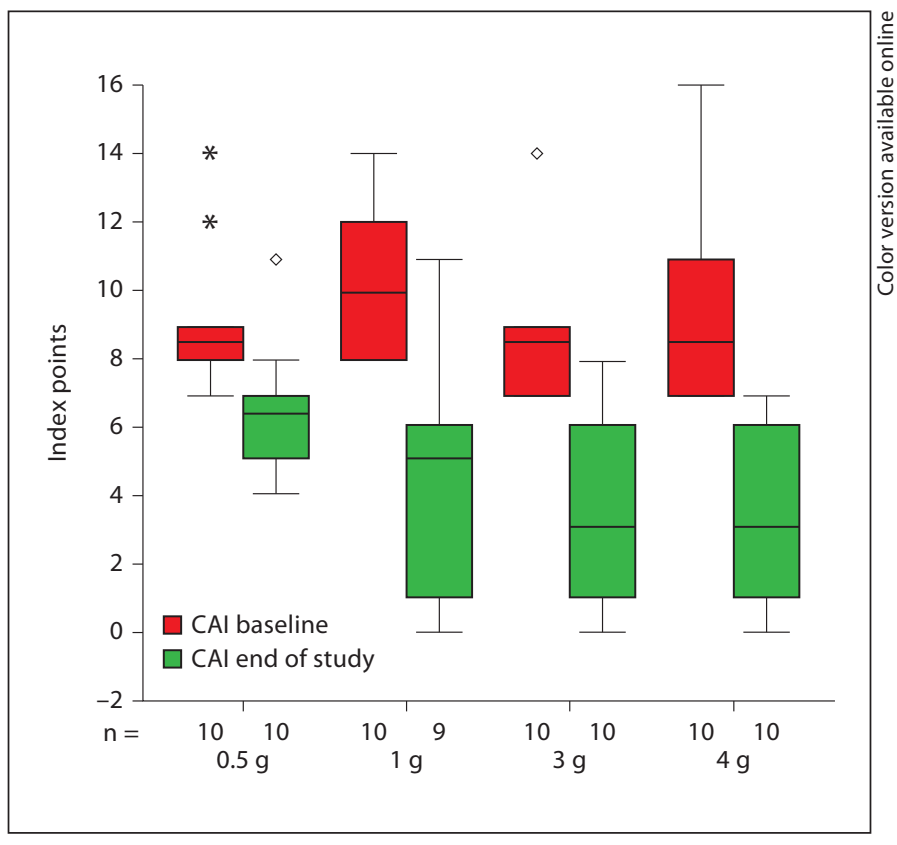

Fig. 4. Changes in the CAI score from baseline to the end of the study. Changes at different doses of delayed intestinal release PC $(\mathrm{rPC})$ are presented as box- and-whisker plots [25th percentile (lower horizontal line), median (middle horizontal line), 75th percentile (upper horizontal line) and extreme values $(\diamond)$ ]. A significant improvement was registered at $1 \mathrm{~g}$ of $\mathrm{rPC}$ compared to the lowest dose of $0.5 \mathrm{~g}$ rPC, with no further differences registered concerning all following doses. The improvements in the CAI score from baseline to the end of the study were 2.5 (IQR 2.0-3.0) in the 0.5-gram dose arm, 7.0 (1.0-7.0) in the 1-gram dose arm, $5.5(4.0-7.0)$ and $6(4.0-9.0)$ in the 4-gram dose arm [35]. $\diamond=\mathrm{Ex}$ treme value, ${ }^{*}=$ outliers.

mensal stool flora within the pouch precipitates the inflammation. The same mechanism of action may apply to the phenomenon of diversion colitis where the PC containing ileal mucus is excluded from entry into the colon.

\section{Proving the Concept in Clinical Trials}

According to the concept that the lack of PC contributes to the pathogenesis of UC, we proposed that the local substitution of PC could enhance or even normalize the mucus PC content and reestablish the mucosal barrier. It is suggested that the application of high concentrations of PC in the lumen may facilitate its integration into the mucus. It may first distribute within the upper mucus layer from where it may be integrated into the lower, densely packed mucus layer to reconstitute the lamellar PC mono- 
layer for the enhancement of the hydrophobic protective barrier against luminal bacteria. An additional aspect of PC supplementation relates to the anti-inflammatory properties of PC [30,31]. It may partition into the mucosal cell plasma membrane as such or is taken up after cleavage to LPC and fatty acids.

PC was shown to decrease TNF- $\alpha$ secretion with consequent NF- $\kappa \mathrm{B}$ deactivation. The mechanism of action of PC is not entirely clear, but there is evidence that via PC, the p65 subunit can interact with F-actin and, thus, prevent NF- $\kappa \mathrm{B}$ activation $[32,33]$.

For the purpose of colonic delivery of missing PC, a delayed release oral formulation was developed [34]. Encapsulation with Eudragit S100 established a pH-dependent release in the distal ileum. It was indeed shown that the colonic mucus PC content increased to normal values [34].

The concept of local supplementation of missing PC in the colonic mucus was evaluated in a first clinical trial in patients with chronic active UC [clinical activity index (CAI) $\geq 4$ ], but without concomitant steroid treatment [34]. In a double-blind, randomized, placebo-controlled study, 60 patients were treated for 3 months with delayedrelease PC $(\mathrm{rPC})$ or placebo $(4 \times 0.5 \mathrm{~g}$ daily). Ninety percent of the rPC-treated patients reached clinical remission (CAI $\leq 3 ; 16$ patients) or showed a $\geq 50 \%$ improvement of their clinical activity (median reduction of the CAI by 7 score points) versus $10 \%$ in the placebo group. This was accompanied by a $\geq 50 \%$ improvement of the endoscopic activity index (EAI) in 11 patients (median improvement of the EAI by 3 score points) compared to no change in the placebo group. The same was true for improvement of histology which was only observed in the $\mathrm{rPC}$ group. The initial median histology score of 3 (IQR $2-4)$ decreased to $2(1-2)(\mathrm{p}<0.0001)$. In parallel, the quality of life improved by $50 \%$ in 16 of 29 evaluated rPCtreated patients versus 2 of 28 patients in the placebo group.

In a dose-finding study with chronic active pancolitis patients, CAI improvement started with $1 \mathrm{~g}$ of rPC daily reaching a plateau at $3 \mathrm{~g}$ and $4 \mathrm{~g}$ rPC daily [35] (fig. 4). This was paralleled by improvement of the EAI. The median time to clinical response was 5 (IQR 2-8) weeks. Mild bloating was registered in $40 \%$ of patients with no difference between the study groups. Three of 10 patients in the 4-gram dose group reported nausea. Other adverse events were not registered.

Even more convincing proof of its clinical efficacy was obtained when the patient population of steroid-refractory UC that was the most difficult to treat was evaluated [36]. At a daily dose of $2 \mathrm{~g}$ of rPC for 3 months, $50 \%$ of the patients could be withdrawn from steroids and at the same time achieved clinical remission (CAI $\leq 3$ ) or a $\geq 50 \%$ CAI improvement compared to $10 \%$ in the placebo-treated group. In total, $80 \%$ of the rPCtreated patients could discontinue the steroid therapy. In parallel with the clinical improvement, $60 \%$ of rPC patients fell below an EAI of 4 and $70 \%$ had an improved EAI of $\geq 50 \%$ compared to only $3 \%$ of the placebo recipients.

\section{Conclusion}

Thus, a new concept for the therapy of UC has been developed based on the observation that a lack of PC in colonic mucus is of key pathogenetic relevance. It is the logical consequence that insufficient PC content would require substitution to maintain the mucosal barrier. Only a delayed-release oral PC preparation is able to deliver PC to the distal ileum. Solubilization with bile acids and incorporation of PC into the mucus enables the reestablishment of a hydrophobic first line of defense.

\section{Disclosure Statement}

The authors declare that no financial or other conflict of intrest exists in relation to the content of the article.

\section{References}

1 Fiochi C: Inflammatory bowel disease: etiology and pathogenesis. Gastroenterology 1998;115:182-205.

2 Podolsky D: Inflammatory bowel disease. N Engl J Med 2002;347:417-429.

3 Rath HC, Schultz M, Freitag R, Dieleman LA, Li F, Linde HJ, Schölmerich J, Sartor RB:
Different subsets of enteric bacteria induce and perpetuate experimental colitis in rats and mice. Infect Immun 2001;69:2277-2285.

$\checkmark 4$ Backhed F, Ley RE, Sonnenburg JL, Peterson DA, Gordon JI: Host-bacterial mutualism in the human intestine. Science 2005;307:19151920.
Kubler I, Koslowski MJ, Gersemann M Fellermann K, Beisner J, Becker S, Rothfuss K, Herrlinger KR, Stange EF, Wehkamp J: Influence of standard treatment on ileal and colonic antimicrobial defensin expression in active Crohn's disease. Aliment Pharmacol Ther 2009;30:621-633. 
-6 Becker T, Loch G, Beyer M, Zinke I, Aschenbrenner AC, Carrera P, Inhester T, Schultze J, Hoch M: FOXO-dependent regulation of innate immune homeostasis. Nature 2010; 463:369-373.

7 Atuma C, Strugala V, Allen A, Holm L: The adherent gastrointestinal mucus gel layer: thickness and physical state in vivo. Am J Physiol Gastrointest Liver Physiol 2001; 280:G922-G929.

-8 Shirazi T, Longman RJ, Corfield AP, Probert CSJ: Mucins and inflammatory bowel disease. Postgrad Med J 2000;76:473-478.

19 Lamont JT: Mucus: the front line of intestinal mucosal defense. Ann N Y Acad Sci 1992; 664:190-201.

10 Johannson MEV, Phillipson M, Petersson J, Velcich A, Holm L, Hansson GC: The inner of the two Muc2 mucin-dependent mucus layers in colon is devoid of bacteria. Proc Natl Acad Sci USA 2008;105:15064-15069.

- 11 Matsuo K, Ota H, Akamatsu T, Sugiyama A, Katsuyama T: Histochemistry of the surface mucous gel layer of the human colon. Gut 1997;40:782-790.

-12 DeSchryver-Kecskemeti K, Eliakim R, Carroll S, Stenson WF, Moxley MA, Alpers DH: Intestinal surfactant-like material. A novel secretory product of the rat enterocyte. J Clin Invest 1989;84:1355-1361.

-13 Butler BD, Lichtenberger LM, Hills BA: Distribution of surfactants in the canine gastrointestinal tract and their ability to lubricate. Am J Physiol 1983;244:G645-G651.

- 14 Hicks AM, DeLong CJ, Thomas MJ, Samuel $\mathrm{M}$, Cui Z: Unique molecular signatures of glycerophospholipid species in different rat tissues analyzed by tandem mass spectrometry. Biochim Biophys Acta 2006;1761:10221029.

15 Hills BA: Surface-active phospholipid: a Pandora's box of clinical applications. Part II. Barrier and lubricating properties. Intern Med J 2002;32:242-251.

16 Lichtenberger LM: The hydrophobic barrier properties of gastrointestinal mucus. Annu Rev Physiol 1995;57:565-583. Review.

$\checkmark 17$ Willumeit R, Schuster A, Iliev P, Linser S, Feyerabend F: Phospholipids as implant coatings. J Mater Sci Mater Med 2007;18: 367-380.

$\checkmark 18$ Guo W, Andersson R, Odselius R, Ljungh A, Wadström T, Bengmark S: Phospholipid impregnation of abdominal rubber drains: resistance to bacterial adherence but no effect on drain-induced bacterial translocation. Res Exp Med 1993;193:285-296.

19 Ehehalt R, Jochims C, Lehmann WD, Erben G, Staffer S, Reininger C, Stremmel W: Evidence of luminal phosphatidylcholine secretion in rat ileum. Biochim Biophys Acta 2004;1682:63-71.
20 Alpers DH, Zhang Y, Ahnen DJ: Synthesis and parallel secretion of rat intestinal alkaline phosphatase and a surfactant-like particle protein. Am J Physiol 1995;268:E1205E1214.

21 Engle MJ, Grove ML, Becich MJ, Mahmood A, Alpers DH: Appearance of surfactant-like particles in apical medium of Caco-2 cells may occur via tight junctions. Am J Physiol 1995;268:C1401-C1413.

22 Ehehalt R, Wagenblast J, Erben G, Lehmann WD, Hinz U, Merle U, Stremmel W: Phosphatidylcholine and lysophosphatidylcholine in intestinal mucus of ulcerative colitis patients. A quantitative approach by nanoElectrospray-tandem mass spectrometry. Scand J Gastroenterol 2004;39:737-742.

23 Braun A, Treede I, Gotthardt D, Tietje A, Zahn A, Ruhwald R, Schoenfeld U, Welsch T, Kienle P, Erben G, Lehmann WD, Fuellekrug J, Stremmel W, Ehehalt R: Alterations of phospholipid concentration and species composition of the intestinal mucus barrier in ulcerative colitis: a clue to pathogenesis. Inflamm Bowel Dis 2009;15:1705-1720.

24 Braun A, Schoenfeld U, Welsch T, Kadmon M, Funke B, Gotthardt D, Zahn A, Autschbach F, Kienle P, Zharnikov M, Grunze M, Stremmel W, Ehehalt R: Reduced hydrophobicity of the colonic mucosal surface in ulcerative colitis as a hint at a physicochemical barrier defect. Int J Colorectal Dis 2011;26: 898-998.

25 Meves A, Stremmel C, Gottschalk K, Fässler $\mathrm{R}$ : The kindling protein family: new members to the club of focal adhesion proteins. Trends Cell Biol 2009;19:504-512.

- 26 Ussar S, Moser M, Widmaier M, Rognoni E, Harrer C, Genzel-Boroviczeny O, Fässler R: Loss of Kindlin-1 causes skin atrophy and lethal neonatal intestinal epithelial dysfunction. PLoS Genet 2008;4:e1000289.

27 Karner M, Ehehalt R, Stremmel W: Retarded release phosphatidylcholine: A new therapeutic option for ulcerative colitis; in A. Dignass, D. Rachmilewitz, E.F. Stange, J.V. Weinstock (eds): Immunoregulation in Inflammatory Bowel Diseases - Current Understanding and Innovation. Heidelberg, Springer, 2007, pp 161-170.

28 Gibson PR, Muir JG: Reinforcing the mucus: a new therapeutic approach for ulcerative colitis? Gut 2005;54:900-903.

29 Nazareth M, Mahadevan U: Phosphatidylcholine in steroid refractory chronic ulcerative colitis - is it all in the mucus? Ann Intern Med 2007;147:603-610.

30 Anes E, Kühnel MP, Bos E, Moniz-Pereira J, Habermann A, Griffiths G: Selected lipids activate phagosome actin assembly and maturation resulting in killing of pathogenic mycobacteria. Nat Cell Biol 2003;5:793-802.
31 Treede I, Braun A, Jeliaskova P, Giese T, Füllekrug J, Griffiths G, Stremmel W, Ehehalt R: TNF-alpha-induced up-regulation of proinflammatory cytokines is reduced by phosphatidylcholine in intestinal epithelial cells. BMC Gastroenterol 2009;9:53.

32 Gutierrez MG, Gonzalez AP, Anes E, Griffiths G: Role of lipids in killing mycobacteria by macrophages: evidence for NFkappaB-dependent and -independent killing induced by different lipids. Cell Microbiol 2009;11:406-420.

- 33 Are AF, Galkin VE, Pospelova TV, Pinaev GP: The p65/RelA subunit of NF-kappaB interacts with actin-containing structures. Exp Cell Res 2000;256:533-544.

34 Stremmel W, Merle U, Zahn A, Autschbach F, Hinz U, Ehehalt R: Retarded release phosphatidylcholine benefits patients with chronic active ulcerative colitis. Gut 2005; 54:966-971.

35 Stremmel W, Braun A, Hanemann A, Ehehalt R, Autschbach F, Karner M: Delayed release phosphatidylcholine in chronic-active ulcerative colitis: a randomized, doubleblinded, dose finding study. J Clin Gastroenterol 2010.;44:e101-e107.

36 Stremmel W, Ehehalt R, Autschbach F, Karner M: Efficacy of retarded release phosphatidylcholine for treatment of chronic, steroid refractory ulcerative colitis. Ann Intern Med 2007;147:603-610.

- 37 Ogasawara N, Kojima T, Go M, Ohkuni T, Koizumi JI, Kamekura R, Masaki T, Murata M, Tanaka S, Fuchimoto J, Himi T, Sawada $\mathrm{N}$ : PPARgamma agonists upregulate the barrier function of tight junctions via a PKC pathway in human nasal epithelial cells. Pharmacol Res 2010;61:489-498.

- 38 Best G, Amberger R, Baddeley D, Ach T, Dithmar S, Heintzmann R, Cremer C: Structured illumination microscopy of autofluorescent aggregations in human tissue. Micron 2011;42:330-335.

39 Elsing C, Winn-Börner U, Stremmel W: Confocal analysis of hepatocellular longchain fatty acid uptake. Am J Physiol 1995; 269:G842-G851.

40 Gotthardt D, Blancheteau V, Bosserhoff A, Ruppert T, Delorenzi M, Soldati T: Proteomics fingerprinting of phagosome maturation and evidence for the role of a Galpha during uptake. Mol Cell Proteomics 2006;5: 2228-2243.

-41 Reinhard L, Rupp C, Riedel HD, Ruppert T, Giese T, Flechtenmacher C, Weiss KH, Kloeters-Plachky P, Stremmel W, Schirmacher P, Sauer P, Gotthardt DN: S100A9 is a biliary protein marker of disease activity in primary sclerosing cholangitis. PLoS One 2012; 7:e29821. 